\title{
Measuring disease activity and patient experience remotely using wearable technology and a mobile phone app: outcomes from a pilot study in Gaucher disease
}

\author{
Aimee Donald ${ }^{1}$, Huseyin Cizer ${ }^{2}$, Niamh Finnegan ${ }^{3}$, Tanya Collin-Histed ${ }^{4}$, Derralynn A. Hughes ${ }^{3}$ and \\ Elin Haf Davies ${ }^{2 *}$
}

\begin{abstract}
Background: Gaucher disease is an inherited lysosomal storage disorder of which there are three subtypes. Type 1 disease has no neurological involvement and is treatable with enzyme replacement therapy. Type 2 disease results in infant death and type 3 disease is a heterogenous disorder characterised by progressive neurological decline throughout childhood and adult life. Endeavours to find a therapy to modify neurological disease are limited by a lack of meaningful clinical outcome measures which are acceptable to patients.

Results: We present results from a pilot study utilising wearable technology to monitor physical activity as a surrogate of disease activity/severity paired with a mobile phone app allowing patients to complete self-reported outcome measures in the real world as opposed to the hospital environment. We demonstrate feasibility of the approach and highlight areas for development with this study of 21 patients, both children and adults.
\end{abstract}

Conclusions: We illustrate, where patients engage in the methodology, a rich dataset is obtainable and useful for proactive clinical care and for clinical trial outcome development.

Keywords: Gaucher, Wearable technology, Mobile health

\section{Introduction}

Gaucher Disease (GD) is one of the most common Lysosomal Storage Disorders resulting from deficiency of the lysosomal enzyme glucocerebrosidase, secondary to mutations in the GBA1 gene. GD is traditionally categorised into three subtypes reflecting age of onset and involvement of the Central Nervous System (CNS); 'Type 1' disease is limited to systemic manifestations primarily of haematopoietic cell lines causing hepatosplenomegaly, bone marrow infiltration and osseous bone pathology but not affecting the CNS, while types 2 and 3 (nGD) involve the brain. CNS pathology in nGD primarily affects the brainstem and deep brain nuclei and progresses to

\footnotetext{
* Correspondence: elin@aparito.com

${ }^{2}$ Aparito, London, UK

Full list of author information is available at the end of the article
}

involve the cerebellum and higher centres [1] resulting in a specific saccadic eye movement defect, altered muscle tone, coordination impairment, tremor and late in disease; ataxia. Patients also have varying severity bone disease, kyphosis, scoliosis, hearing impairment and other nonneurological features such as lung infiltration or cardiac disease.

Disease severity in nGD is typically described by clinicians using traditional examination techniques and, more recently, the modified Severity Scoring Tool (mSST) [2]. Although useful, these measures fail to account for the functional impact of disease on patients and only give a momentary account of function, overlooking disease fluctuations and the factors which provoke them.

(c) The Author(s). 2019 Open Access This article is distributed under the terms of the Creative Commons Attribution 4.0 International License (http://creativecommons.org/licenses/by/4.0/), which permits unrestricted use, distribution, and 
Wearable technologies enable continuous monitoring of physical activity in a daily-living context, and smartphone apps can facilitate recording of Patient Reported Outcomes (PROs) and events, in real-time, to account for variable function and memory recall. Here we report the preliminary data and experience of an approach using this technology to inform our understanding of disease activity in nGD by comparing outcomes and activity within and between patients with nGD and in comparison, to a small group of patients with Type 1 Gaucher Disease.

\section{Results}

Twenty-one patients were enrolled in the study; five patients with Type 1 Gaucher Disease age 13 yrs. - 42 yrs. (mean 24.8 yrs) and sixteen patients with nGD aged 5 yrs- 48 yrs. (mean $21 \mathrm{yrs}$ ). Although just a convenient sample they were a relatively well age-matched but not sex matched cohort. This cohort accounts for $57 \%$ of all known UK nGD and 1.8\% of the estimated UK Type 1 disease patient cohort.

Summary results are detailed in Table 1.

\section{6 minute walk test (6MWT)}

Fifteen patients completed the 6MWT; Z scores were calculated to summarise the data, using calculations by Geiger et al. [3]. The mean distance walked by nGD patients $(n=12)$ was $391 \mathrm{~m}$ (median $377 \mathrm{~m}$; SD 122.707) and a mean $\mathrm{z}$-score of -5.57 (age range 642 yrs). Type 1 patients $(n=3)$; mean distance was $475.67 \mathrm{~m}$ (age range: $18-42 \mathrm{yrs}$ ); with a mean $\mathrm{z}$-score of -3.99. A difference of 1.58 , BCa $95 \% \mathrm{CI}[-.908$, 3.805] between the two groups is identified but not significant $\mathrm{t}(14)=1.016, p=.327$. There was no statistical correlation between disease severity (as measured by $\mathrm{mSST})$ and $6 \mathrm{MWT}(\mathrm{\tau}=-.237,95 \% \mathrm{BCa} \mathrm{CI}[-.555$, .180 ], $p=.206$ ). All but one patient showed a 6MWT score $>2$ SD from the normative values irrespective of disease type.

\section{GaitRite/Zeno walkway}

The gait analysis was undertaken as a sub study and will be reported separately.

\section{Wearable activity monitoring}

Three patients had no 'active days' recorded (defined as days where $>4$ epochs had recorded step data) and were thought to be non-compliant with wearing the device beyond the day of recruitment, these were all nGD patients.

Mean number of active days was 31.19 across the whole cohort (GD1 and nGD combined); median of 16 active days (SD 45.59). Patients with at least five 'active days' were included in more extensive analysis; $n=15 ; 5$ with Type 1 disease and 10 with nGD; mean number of active days in each group was similar; 45.4 in the type 1 group and 42.3 in nGD.

Wearable device data were calculated into three different variables.

- Average Daily Maximum = ADM: The maximum number of steps per 30 min epoch on each active day, averaged over all active days in the month.

- Average Daily Steps = ADS: The total number of steps (from active days only) over a month, divided by the number of active days.

- Average Steps per Epoch = ADE: The total number of steps in a day divided by the number of active epochs; averaged over the number of active days in the month.

Across the whole cohort ADM was 852.1, ADS was 5293.4 and ADE was 290.0 (Table 2). When splitting GD1 and nGD data a considerable difference is noted, although not statistically significant on t-test or MannWhitney-U Test, with the ADS being nearly 2.5 times higher in the GD1 vs the nGD cohort. A greater difference was noted in the ADM (1537.25 vs 554.29) indicating that patients with Type 1 disease are able to perform

Table 1 Summary Demographics of patients enrolled in wearable activity monitoring study

\begin{tabular}{|c|c|c|c|}
\hline & $\operatorname{ALL}(n=21)$ & $\mathrm{nGD}(n=16)$ & GD1 $(n=5)$ \\
\hline Age (yr) & $\begin{array}{l}\text { Mean: } 22.3 \\
(5-48)\end{array}$ & $\begin{array}{l}\text { Mean: } 21 \\
(5-48)\end{array}$ & $\begin{array}{l}\text { Mean: } 24.8 \\
(13-42)\end{array}$ \\
\hline $\operatorname{Sex}(M: F)$ & $6: 15$ & 2:14 & $4: 1$ \\
\hline Genotype & & $\begin{array}{l}\text { 75\% L444P/L444P (others mutations include: } \\
\text { D409H, R463C, RecNcil, E233D) }\end{array}$ & $\begin{array}{l}\text { Mutations: L444P, N370S, F397S, 55bpdel, } \\
\text { 2x large deletions }\end{array}$ \\
\hline mSST & $\begin{array}{l}\text { Mean: } 4.76 \\
(0-17)\end{array}$ & $\begin{array}{l}\text { Mean: } 6.06 \\
(0.5-17)\end{array}$ & $\begin{array}{l}\text { Mean: } 0.6 \\
(0-3)\end{array}$ \\
\hline $\begin{array}{l}6 \mathrm{MWT} \\
(n=15)\end{array}$ & & $\begin{array}{l}(n=12) ; \text { the mean distance was } 391 \mathrm{~m} \\
\text { (median } 377 \mathrm{~m} \text {; SD 122.707) }\end{array}$ & $\begin{array}{l}(n=3) \text {; the mean distance was } 475.67 \mathrm{~m} \\
\text { (age range: } 18-42 \mathrm{yrs}) ;\end{array}$ \\
\hline 6MWT Z score & & -5.57 (age range: $18-42 \mathrm{yrs}$ ); & -3.99 (age range 6-42 yrs) \\
\hline
\end{tabular}


Table 2 Activity parameters by disease group - Comparison by Mann Whitney U-Test

\begin{tabular}{llll}
\hline Cohort $(n=15)$ & ADM & ADS & ADE \\
\hline All & 852.1 & 5293.4 & 290.0 \\
GD1 $(n=5)$ & 1537.25 & 9805.52 & 489.711 \\
nGD $(n=10)$ & 554.29 & 3933.64 & 260.26 \\
T-test & $.985 p=.370$ & $.885 p=.413$ & $.686 p=516$ \\
Mann Whitney U-Test & $p=.768$ & $p=.953$ & $p=.859$ \\
\hline
\end{tabular}

a much higher intensity of activity in any given 30-min period.

Patients did not all complete the same baseline measures; correlation was performed in patients who had wearable activity monitoring of $>5$ active days, 6MWT at baseline and a Gaitrite/Zeno Walkway assessment $(n=10)$. All patients included have nGD. The correlation coefficients were small between all step parameters and the other disease severity measures (see Table 3).

Adherence to device use was not correlated with age; however, Pearson correlation coefficients between average step counts and age; ADM and age $r=-.592$, $p=.071$; ADS and age $\mathrm{r}=-.593, p=.071$ and $\mathrm{ADE}$ and age $\mathrm{r}=-.573, p=.084$ is large. This suggests that older patients, in this cohort of Gaucher patients, are less active, mSST scores in patients with nGD do deteriorate over time [2] but are not directly correlated with age (some patients with nGD are more severe in childhood) and a low correlation between age and mSST was seen when measured by Pearson's correlation $\mathrm{r}=-.338$ $p=.340$.

Table 3 Correlation of disease severity parameters with wearable activity monitoring results in nGD patients

\begin{tabular}{|c|c|c|c|}
\hline Kendall's Tau & $\begin{array}{l}\text { Average Daily } \\
\text { Maximum }\end{array}$ & $\begin{array}{l}\text { Average Daily } \\
\text { Steps }\end{array}$ & $\begin{array}{l}\text { Average Steps } \\
\text { per Epoch }\end{array}$ \\
\hline \multicolumn{4}{|l|}{ 6MWT } \\
\hline $\begin{array}{l}\text { Correlation } \\
\text { Coefficient }\end{array}$ & -0.09 & -0.045 & 0 \\
\hline Sig. (2-tailed) & 0.719 & 0.857 & 1 \\
\hline $\mathrm{N}$ & 10 & 10 & 10 \\
\hline \multicolumn{4}{|l|}{ mSST } \\
\hline $\begin{array}{l}\text { Correlation } \\
\text { Coefficient }\end{array}$ & 0.068 & -0.068 & -0.205 \\
\hline Sig. (2-tailed) & 0.787 & 0.787 & 0.417 \\
\hline $\mathrm{N}$ & 10 & 10 & 10 \\
\hline \multicolumn{4}{|c|}{ Velocity (GAITRite/Zenomat) } \\
\hline $\begin{array}{l}\text { Correlation } \\
\text { Coefficient }\end{array}$ & -0.244 & -0.156 & -0.111 \\
\hline Sig. (2-tailed) & 0.325 & 0.531 & 0.655 \\
\hline $\mathrm{N}$ & 10 & 10 & 10 \\
\hline
\end{tabular}

When factoring the effects of bone disease and kyphosis, age was not correlated, however ADS and severity of bone disease were correlated; Kendalls $\tau=-.538$; $p=.012$, and kyphosis to ADS showed a moderate correlation; Kenadalls $\tau=-.367 p=.080$ although not statistically significant.

\section{Phone application results}

Three patients reported no events and didn't respond to any of the app PROs and were considered to be nonadherent with phone application usage; one patient did not engage with the wearable also (nGD patient), one patient had difficulty synchronising the phone app to the device and reported they had lost data ( $\mathrm{T} 1$ patient) and the other patient felt too busy to use the app (type 1 patient).

\section{Event reporting}

Thirteen patients; nGD $n=9$ (56\%) and GD1 $n=2$ (40\%), reported 'events' using the app on at least one occasion. There were 210 events reported in total, ranging from 1 to 102 per patient. The majority of events were recorded by nGD patients and the most frequently reported event was 'bone pain'. Only two events (sleep impairments) were reported by GD1 patients. Details of the reported events are presented in Fig. 1. All events reported by patient and details of the 'other' events can be found in Table 4 and Table 5.

The two patients who reported the greatest number of bone pain events were both nGD patients, one patient (patient 018) with very severe bone disease requiring multiple surgical interventions, the other patient (patient 005) has relatively minimal objective evidence of bone disease but was the highest app user. The high reporting rate may, in part, reflect a differing event reporting threshold to other patients. A further factor may reflect time period of app usage. Patient 005 had a 318-day reporting period compared to a 44-day reporting period for patient 018. As such; the ratio of bone events reported was 0.12 events per day compared with 1.23 events reported per day for patient 018.

It is important to note that 7 out of the 9 nGD patients reported bone pain as an event indicating that this is a significant disease feature across the cohort, even though it might be over shadowed by other clinical manifestations.

Likewise, sleep impairments were reported by 5 out of the 9 patients a total of 49 times (26\%). Patients were asked to report sleep 'events' via the question 'did you sleep poorly?', if they responded 'yes' they could detail the reason they attributed; the majority of responses reflected 'restlessness', 'anxiety', excessive thoughts, feeling too hot or having pain. Whether the sleep impairment was caused by bone pain specifically is not clear, 


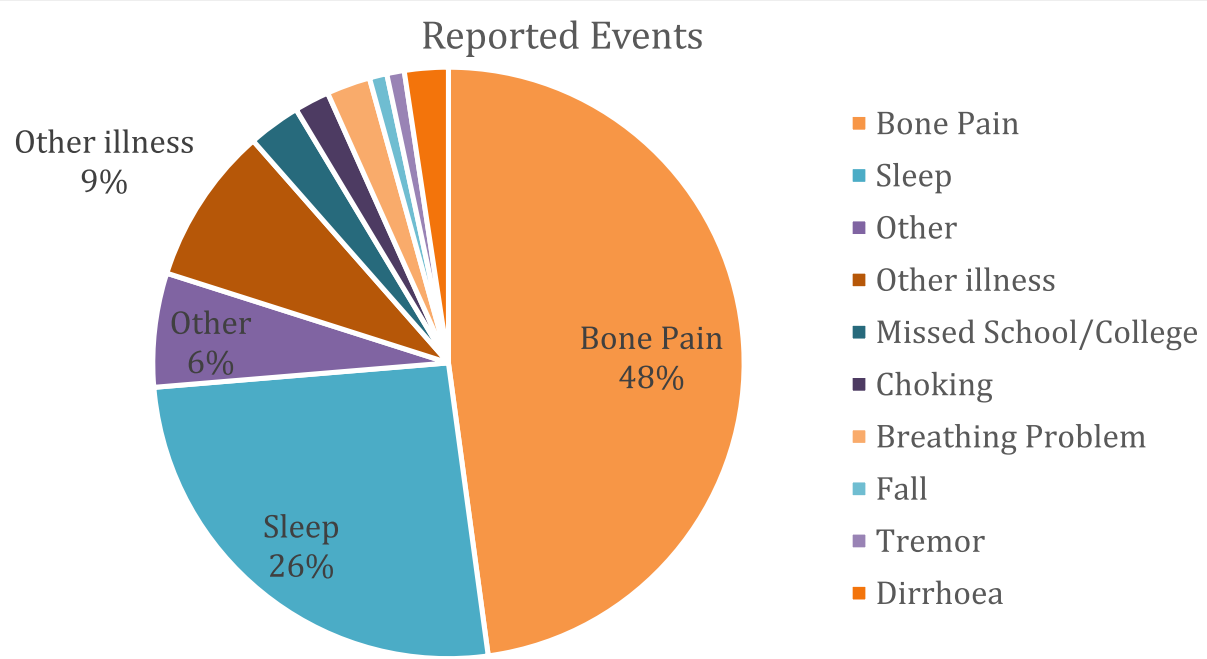

Fig. 1 Frequency of reported events via the phone app. Legend: Pie chart showing reported events, colour coded by frequency as percentage and colour coded to depict bone pain, sleep, other event, other illness, missed school, choking, breathing, fall, tremor, diarrhoea

but an association should be considered. The combined impact of both of these events can be seen to have significant impact on day-to-day physical activity.

Ratios of events:reporting day appear to reflect clinical findings of disease activity, however also highlight the

Table 4 Events Reported on App; Event Type and Number

\begin{tabular}{|c|c|c|c|}
\hline $\begin{array}{l}\mathrm{Pt} \\
\mathrm{N}:\end{array}$ & $\begin{array}{l}\text { Disease } \\
\text { Type }\end{array}$ & $\begin{array}{l}\text { No. of } \\
\text { Events }\end{array}$ & $\begin{array}{l}\text { Event type } \\
\text { (number reported) }\end{array}$ \\
\hline 002 & 3 & 6 & $\begin{array}{l}\text { Bone Pain (1), Fall (1), Absence from education/ } \\
\text { work (1); Tremor (1); Other Illness (1); Sleep } \\
\text { Impairment (1); Other: Sleepy and clumsy } \\
\text { after infusion }\end{array}$ \\
\hline 003 & 3 & 4 & $\begin{array}{l}\text { Bone Pain (2); Absence from education/work } \\
\text { (1); Other illness (1) }\end{array}$ \\
\hline 004 & 3 & 8 & $\begin{array}{l}\text { Bone Pain (2); Absence from education/work (1); } \\
\text { Other illness (1); Sleep Impairment (4) }\end{array}$ \\
\hline 005 & 3 & 102 & $\begin{array}{l}\text { Bone Pain (38); Breathing Problems (4); Choking } \\
\text { Episodes (4); Diarrhoea (5); Fall (1); Other Illness } \\
\text { (10); Sleep Impairment (31); Tremor (1); Other: } \\
\text { Anxiety/Depression (3); Headache (1); Toothache } \\
\text { (2); Swallowing difficulty (1); General lethargy } \\
\text { post infusion (1) }\end{array}$ \\
\hline 008 & 3 & 1 & Absence from education/work (1) \\
\hline 009 & 3 & 2 & Bone Pain (1); Other illness (1) \\
\hline 010 & 3 & 3 & Bone Pain (1); Absence from education/work (2) \\
\hline 013 & 3 & 10 & $\begin{array}{l}\text { Sleep impairment (3); Other illness (2); Other (5): } \\
\text { Sore throat, Headache, Restless legs, Abdominal } \\
\text { Pain, Constipation }\end{array}$ \\
\hline 018 & 3 & 70 & $\begin{array}{l}\text { Bone Pain (54); Breathing Problems (1); Sleep } \\
\text { impairment (13); Other (2): Swallowing difficulty, } \\
\text { Knee pain. }\end{array}$ \\
\hline 020 & 1 & 1 & Sleep impairment (1) \\
\hline 021 & 1 & 1 & Sleep impairment (1) \\
\hline
\end{tabular}

symptomatic experience of patients which may be overlooked clinically by traditional monitoring or failure of patient recall in a clinic setting.

\section{Patient reported outcomes (PROs)}

The results from the PRO's in the form of mean scores (in relation to the scoring reference ranges) and statistical differences between disease groups are detailed in Table 6 and Fig. 2.

The CHU9D showed a statistically significant difference between disease groups, nGD patients reporting overall lower health-related quality of life. Figure 2 shows that fatigue ("tired"), as a CHU9D measured domain, showed the highest scores in both patient groups, but a greater range in the patients with Type 1 Gaucher disease.

Table 5 'Other' Events reported

\begin{tabular}{ll}
\hline Other Description & Frequency \\
\hline Clumsy & 1 \\
Headache & 2 \\
Swallow & 2 \\
Fatigue & 1 \\
Depression & 1 \\
Anxiety & 2 \\
Restless Legs & 1 \\
Abdominal Pain & 1 \\
Constipation & 1 \\
New co-morbid diagnosis & 1 \\
\hline
\end{tabular}


Table 6 Patient Reported Outcomes mean scores by disease type

\begin{tabular}{|c|c|c|c|c|c|c|}
\hline \multirow[t]{2}{*}{ PRO } & \multicolumn{2}{|c|}{$\begin{array}{l}\text { Number of } \\
\text { Patients } \\
\text { Completed }\end{array}$} & \multicolumn{2}{|l|}{ Mean Score } & \multirow[t]{2}{*}{$\begin{array}{l}\text { Independent t-test } \\
\text { between groups }\end{array}$} & \multirow[t]{2}{*}{ PRO ref. range } \\
\hline & $\begin{array}{l}G D \\
1\end{array}$ & nGD & GD 1 & $\begin{array}{l}\mathrm{nGD} \\
\text { patients }\end{array}$ & & \\
\hline CHU9D* & 3 & 10 & $\begin{array}{l}0.93 \\
(\mathrm{SE}=.016)\end{array}$ & $\begin{array}{l}0.81 \\
(S E=0.025)\end{array}$ & $\begin{array}{l}\mathrm{t}(11)=2.43 \\
p=.033\end{array}$ & $\begin{array}{l}\text { 0.33-1 } \\
\text { (higher score = perfect health) }\end{array}$ \\
\hline PedsQL MFS* & 3 & 10 & & & & $0-100$ \\
\hline General Fatigue & & & $\begin{array}{l}69.44(\mathrm{SE} \\
2.78)\end{array}$ & $\begin{array}{l}56.25(\mathrm{SE} \\
6.37)\end{array}$ & $\begin{array}{l}\mathrm{t}(11)=1.09 \\
p=.298\end{array}$ & \\
\hline Sleep Fatigue & & & $\begin{array}{l}56.99 \\
\text { (SE7.35) }\end{array}$ & $\begin{array}{l}58.08 \text { (SE } \\
8.32)\end{array}$ & $\begin{array}{l}\mathrm{t}(11)=-.07 \\
p=.945\end{array}$ & \\
\hline Cognitive Fatigue & & & $\begin{array}{l}69.44(\mathrm{SE} \\
15.47)\end{array}$ & $\begin{array}{l}57.08 \text { (SE } \\
4.89)\end{array}$ & $\begin{array}{l}\mathrm{t}(11)=1.04 \\
p=.321\end{array}$ & \\
\hline Self-esteem: Rosenberg Self-worth* & 2 & 10 & $\begin{array}{l}14.5(\mathrm{SE}= \\
0.5)\end{array}$ & $\begin{array}{l}16.5(\mathrm{SE}= \\
0.5)\end{array}$ & $\begin{array}{l}\mathrm{t}(10)=-1.70 \\
p=.119\end{array}$ & $\begin{array}{l}0-30 \\
(<15=\text { Low self-esteem })\end{array}$ \\
\hline Perceived Stress Scale* & 2 & 10 & 6.5 (SE 4.5) & $\begin{array}{l}22.7 \text { (SE } \\
6.17)\end{array}$ & $\begin{array}{l}t(10)=-3.38 \\
p=.007\end{array}$ & $\begin{array}{l}\text { 0-40 } \\
\text { (higher score = greater perceived stress) }\end{array}$ \\
\hline $\begin{array}{l}\text { REM Sleep Behaviour Disorder } \\
\text { Questionnaire }\end{array}$ & 5 & 11 & 1.4 (SE .872) & $\begin{array}{l}5.64(\mathrm{SE} \\
.877)\end{array}$ & $\begin{array}{l}\mathrm{t}(14)=-2.94 \\
\boldsymbol{p}=. \mathbf{0 1 1}\end{array}$ & $>5=$ problematic sleep \\
\hline Pittsburgh Sleep Quality Index & 5 & 10 & 3.8 (SE 2.17) & 8.8 (SE 1.76) & $\begin{array}{l}\mathrm{t}(13)=-1.90 \\
p=.079\end{array}$ & $>5=$ problematic sleep \\
\hline $\begin{array}{l}\text { Sleep Disturbance Scale for } \\
\text { Children }\end{array}$ & 0 & 3 & NA & 72.67 & NA & $\begin{array}{l}\text { Total T-Score }>70 \text { pathological* (Subdomains } \\
\text { scored identically) }\end{array}$ \\
\hline
\end{tabular}

Note 1: Data from the 'Global self-worth' scale was not analysed as no patients under the age of fourteen completed this.

*PROs completed on the Aparito phone application.

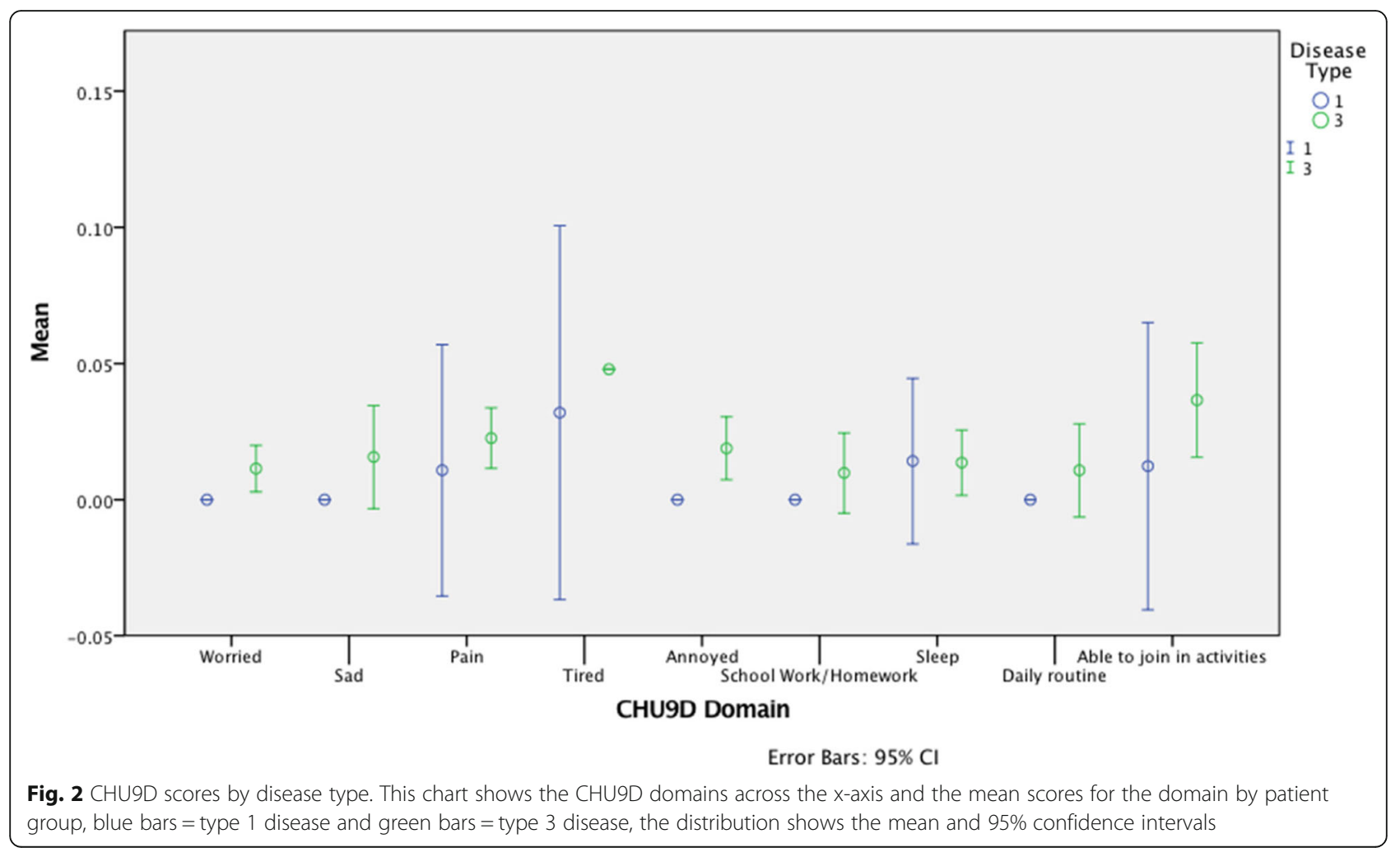


Correlation between domain responses is demonstrated when we look at the most active PRO responder; patient 005 who showed consistency between responses measured in the scale as illustrated in Fig. 3.

Although not statistically significant; patients with nGD generally reported slightly higher levels of fatigue as measured by the MFS. Domains of fatigue; 'general', 'sleep' and 'cognitive' were consistent in suggesting poor sleep patterns across most patients with no single domain dominating deficits.

The sleep specific PROs showed pathological scores in the nGD group which may reflect underlying neuropathology and contribute to fatigue scores. Problematic sleep as detected by the REM Sleep Behaviour Disorder Questionnaire (RSBDQ) was detected in patients with nGD but not in patients with Type 1 Gaucher disease, while the Pittsburgh Sleep Quality Index did show a difference between disease groups, but not quite statistical significance. This perhaps suggests the nature of sleep disturbance in nGD is specific (as measured by the RSBDQ), further analysis of this will follow as a study extension.

Results from the sleep-specific PROs were correlated with PedsQL MFS and with 'sleep disturbance' event reporting through the phone app. Table 7 details the mean scores for these parameters; correlation was identified between the self-reporting questionnaires and the number of sleep events reported by patients.

Perceived stress was also significantly higher in patients with nGD than patients with type 1 Gaucher disease (although only 2 patients with $\mathrm{T} 1$ disease responded to the questionnaire at baseline). Two patients showed specific fluctuations in PSS over time; patient 05 had a decline in stress score (PSS) in February 2017 which was correlated with a reduction in the number of events recorded during this period (Fig. 4). Patient 14 who also showed a change over time, did not record any events at all to be able to determine the nature of the change in perceived stress.

\section{Correlation of activity/PROs/events}

Patient 005 was the most active user of both the wearable device and the app and is used to illustrate the utility of correlating step data, event and PROs in combination. At the time of peak difficulties in "joining in activities" and "performing daily routines" as reported in the CHU9D (November 2016) a decline in step count is also observed (Fig. 5). When correlated with number and type of reported 'events' via the app at this time, the patient reports poor sleep due to increasing anxiety symptoms, demonstrating the possible enrichment and interpretation of both the PRO and activity data by using the real-time event reporting, and giving objective illustration of the overall picture for clinical staff to see.

\section{Discussion}

The wearable device variables (Average Daily Maximum $=$ ADM; Average Daily Steps $=$ ADS; Average Steps per Epoch $=\mathrm{ADE}$ ) measured in this study calculated important differences between the nGD and GD1

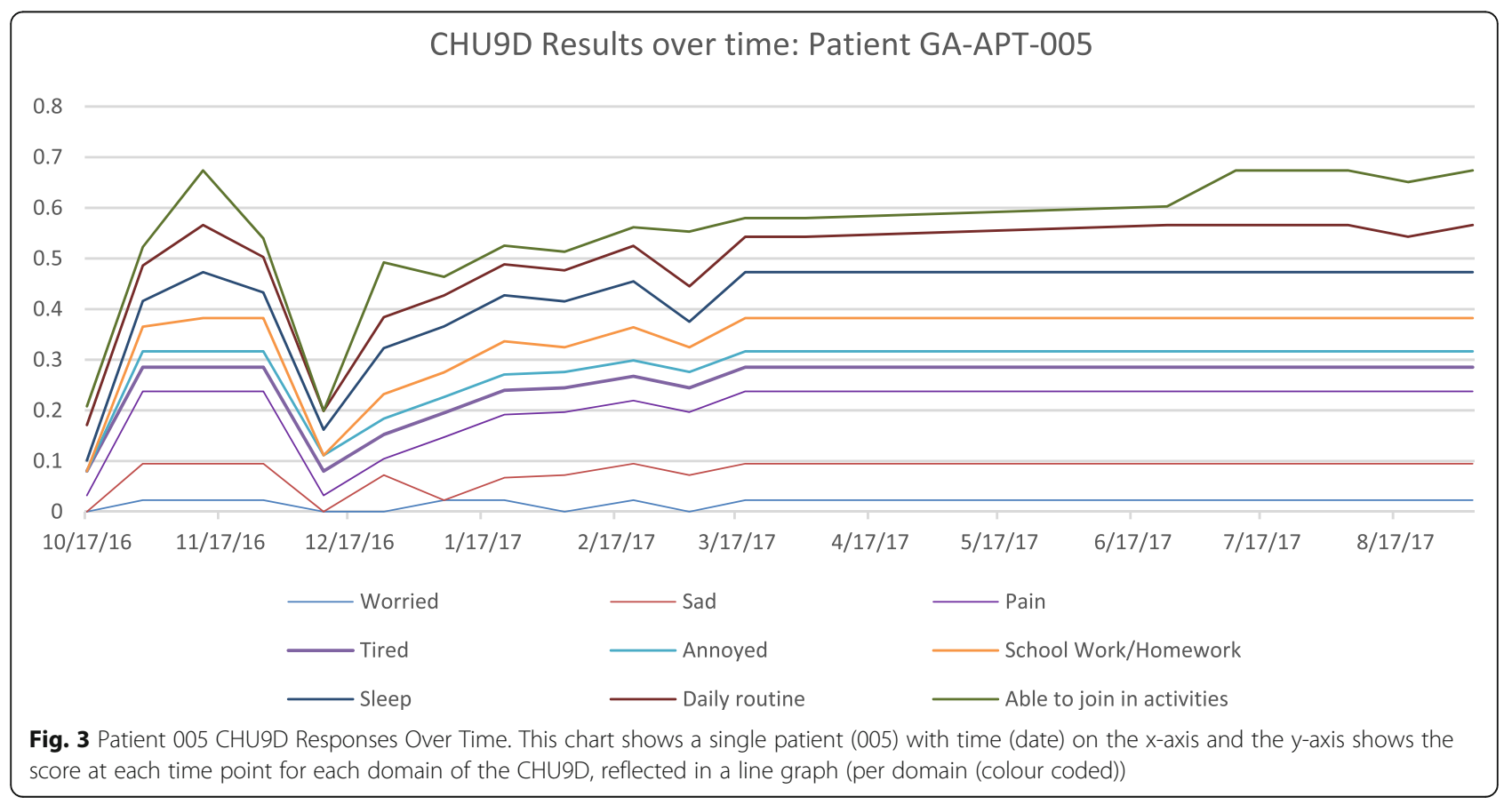


Table 7 Sleep assessment tool correlations

\begin{tabular}{lllllc}
\hline & RSBDSQ & PSQI & Mean Total MFS & MFS Sleep Sub-score & Total Sleep Events Reported \\
\hline Total Mean & 4.31 & 7.1333 & 55.86 & 52.8 & 0.16 \\
Type 1 Mean & 1.4 & 3.8 & 65.28 & 56.94 & .5 \\
nGD Mean & 5.64 & 8.8 & 52.33 & 51.25 & 5.2 \\
Pearsons R & $.660(n=14)$ & $.735(n=13)$ & $-1.66(n=12)$ & $-.729(n=11)$ & \\
(Total Sleep Events reported) & & & & 0.011 & \\
$\mathrm{p}$ & .010 & .004 & 0.721 & \\
\hline
\end{tabular}

cohort. The ADS was nearly 2.5 times higher in the GD1 cohort than the nGD cohort, with an even greater difference noted in the ADM (1537.29 vs 554.29), indicating that patients with GD1 are able to perform a much higher intensity of activity in any given 30 -min period. High intensity activity requires not only physical strength but also coordination. The presence of ataxia, tremor etc. might therefore impact on the patient's ability to partake in high intensity activity regardless of physical strength alone. Although some correlation between ADS and bone disease was seen, a more detailed study with greater patient numbers would be required to determine the nature of the difference in step counts seen, it is likely that the combined effects of bone disease and neurology are contributory. As this study has highlighted, bone pain in this cohort of nGD patients has a greater functional impact on activity and quality of life than perhaps previously recognised. The gait analysis data offered by the GAITRite and Zeno Walkway although show a difference between disease groups, with identifiable gait parameter deficits suggestive of a neurological basis of impairment, are not adequately defined to enable correlation with the step data. Poor sleep and fatigue are also likely to be contributing factors reducing total amount of physical activity each day. This observation demonstrates the value of combining the PRO and event reporting in the app with the wearable device and the importance of monitoring more general aspects of quality of life in multisystem rare neurodegenerative disease.

When comparing ADS values in this cohort to other studies it is noted that nGD patients were much less active (mean ADS of 3933.64) compared to those reported in cohorts of patients with Multiple Sclerosis (mean = 5478) [4] but similar to the mean ADS reported in patients with Pompe disease (unassisted ambulation); $\mathrm{ADS}=3408$ [5].

The phone app patient reporting aspect of the study showed broader utility than first imagined. Not only were the PRO assessments considered to be easier for

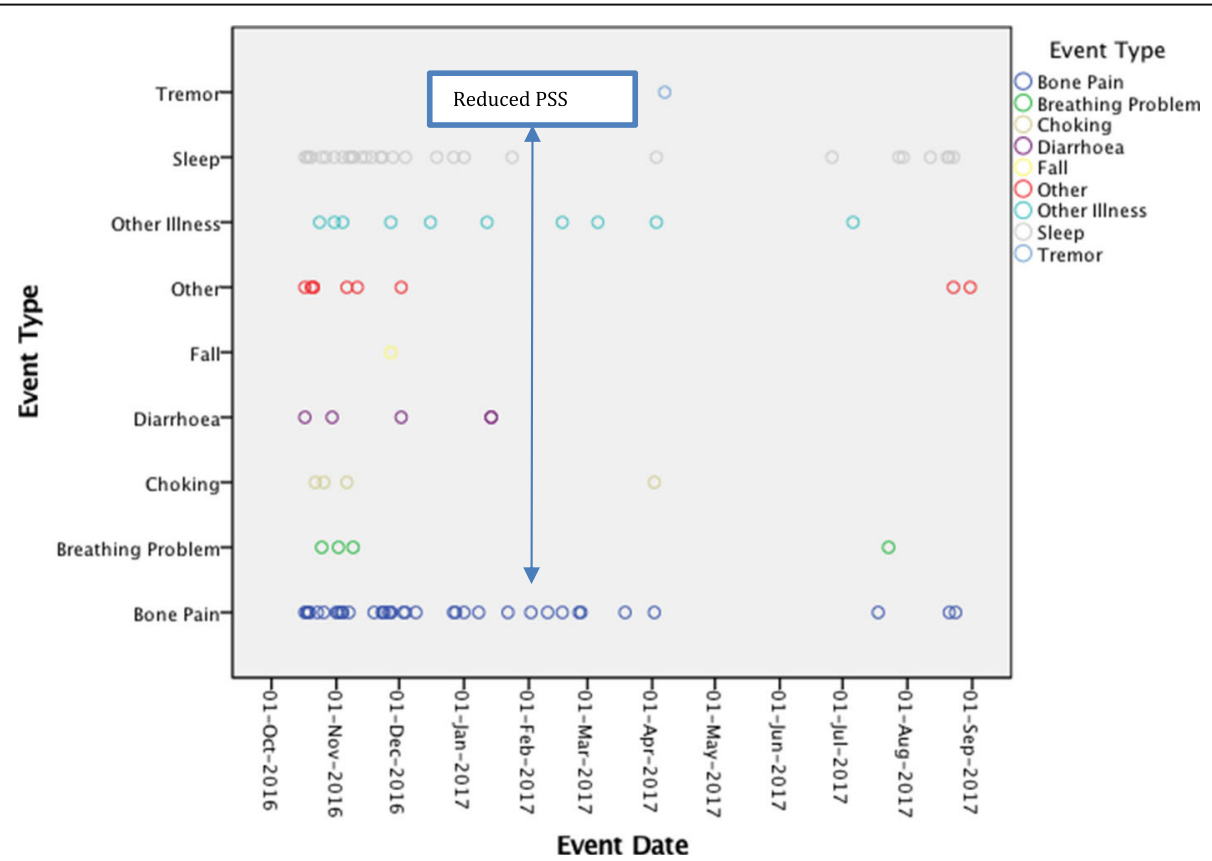

Fig. 4 Patient 005 Reported Events. This graph records the reported events (y-axis) patient 005 recorded by date ( $x$-axis) with a highlight of the date at which the perceived stress score (pss) value reduced 


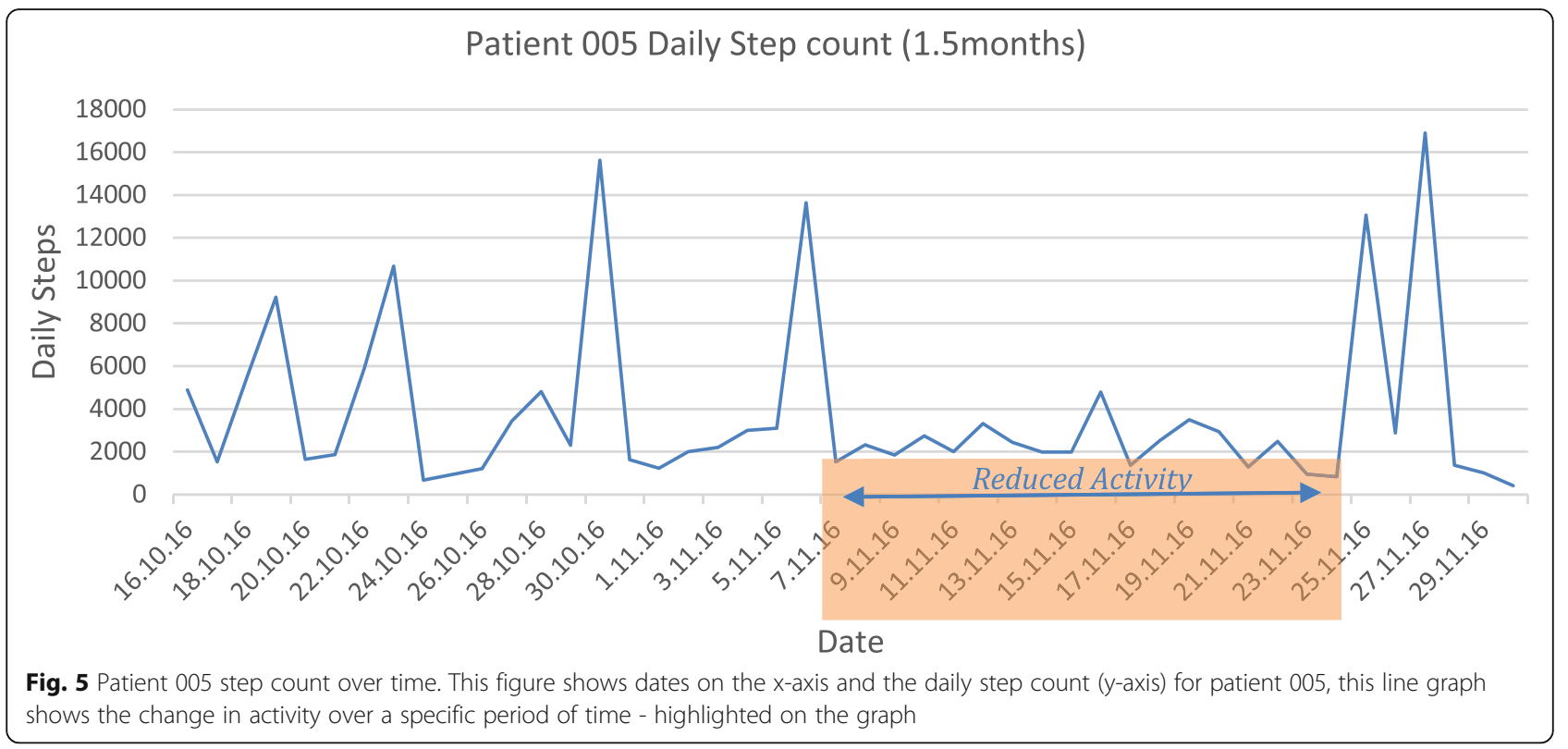

patients to interact with and more likely to give a reliable reflection of experience, the event reporting offered patients the opportunity to highlight functional aspects of their disease experienced perhaps previously overlooked. nGD studies historically have focussed on neurological symptoms and here patients reported fatigue and bone pain as significant symptoms of disease.

The sleep impairments reported by patients correlated well with formal validated measures of sleep and although don't offer detail on the nature of impairment do provide an opportunity to examine the impact of sleep to activity. This specific group of patients have an extremely low frequency of seizures but in other cohorts the effect of a seizure on activity and sleep, for example, could be identified and then the effect of therapeutic intervention recorded in a relatively objective way in real time. Utilising a wearable device to measure sleep parameters in future larger studies is planned.

This pilot study primarily served to assess the feasibility of using such technology in this patient group. Long term adherence in using the wearable device, and consistent engagement with the app impacted on the analysis. It wasn't entirely clear whether events weren't reported because they weren't experienced, the patient didn't want to report them or didn't fully understand how to do so on the app. Patient adherence to use of the technology appeared to be impacted by three main factors;

- Technical failures

- Training and on-going support

- Patients capability to cope / being easily overwhelmed.
Some technical failures and limitations impacted on the patient's ability to achieve high engagement and adherence; especially download and Bluetooth synchronisation of the app across different mobile handsets. This was compounded by the fact that patients needed a lot of training and on-going support with the technology which was not always possible to provide quickly (with a small study team and patients distributed throughout the UK at several different centres), along with what seemed to be a low threshold for getting overwhelmed with instructions. A complete analysis of the relationship of engagement to IQ wasn't possible as formal IQ testing wasn't undertaken as part of the study, however, using clinical judgement and historical cognitive assessments a relationship appeared present between those patients with greater cognitive deficits and lower engagement. Such patients have very specific intellectual impairments and strive for independence. Although they were encouraged to seek support in undertaking study activities (using the app and device), often they lacked motivation to seek help in this regard. This was less relevant in the paediatric age group where the technology was managed by parents. For younger children however, devices were often too big for the wrist, were lost easily or damaged more easily and required frequent replacement.

Some patients also reported that the phone app offered no feedback regarding data obtained; many young adults wanted to be able to track their own activity and parents felt a symptom diary would be useful for recalling events during hospital appointments. Such features had intentionally been excluded from the app interface so as to limit the exposure of unfiltered raw data to patients however future deployment should address this request. 


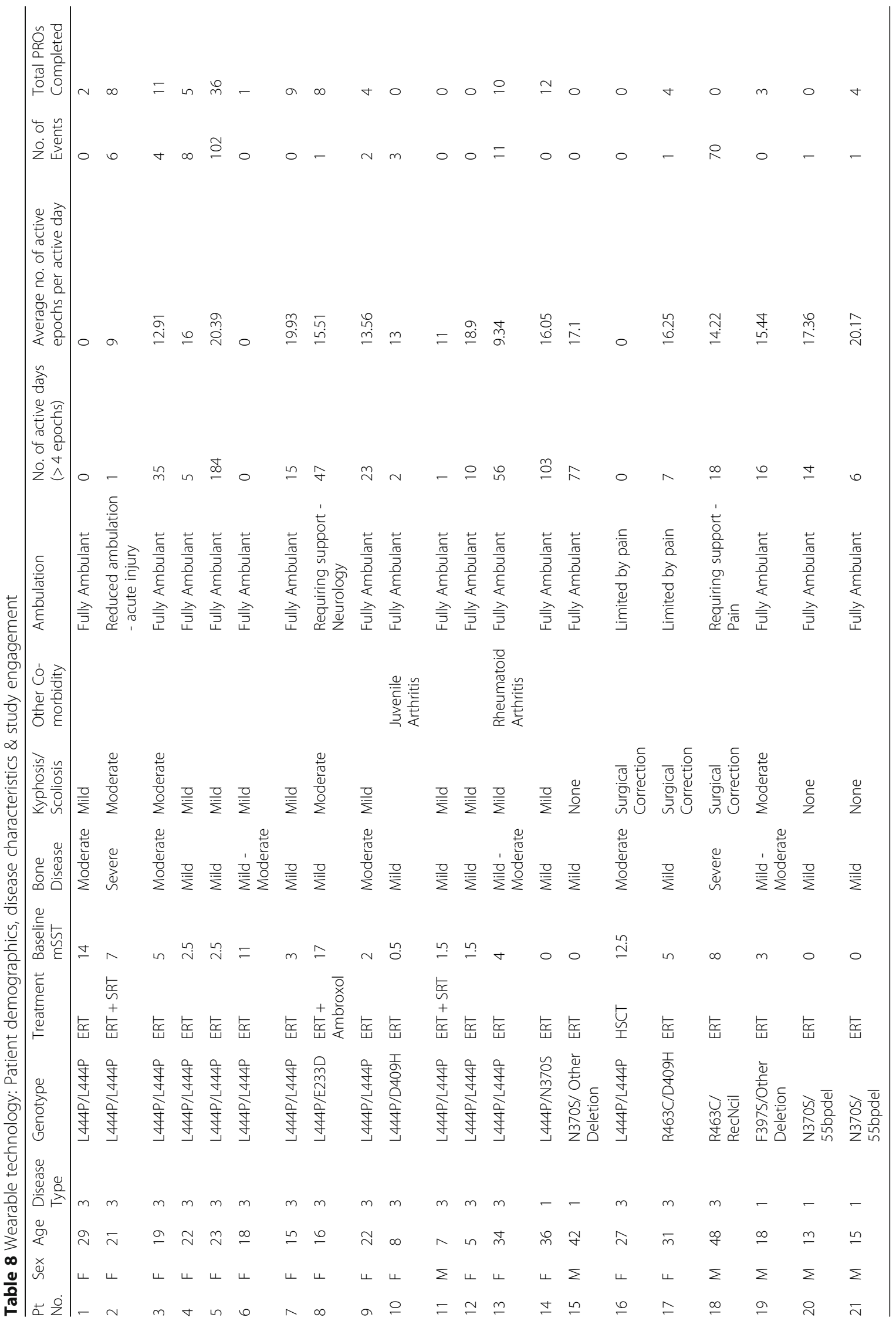


Table 9 Patient Reported Outcomes and Quality of Life Scale details and scheduling

\begin{tabular}{|c|c|c|c|c|}
\hline Patient Reported Outcomes & Domains & Function & Age Group & $\begin{array}{l}\text { Timing } \\
\text { Schedule } \\
\text { (Days) }\end{array}$ \\
\hline $\begin{array}{l}\text { CHU 9D } \\
\text { (Child Health Utility 9D) }\end{array}$ & 9 & $\begin{array}{l}\text { Health-related Quality } \\
\text { of Life }\end{array}$ & $\begin{array}{l}\text { Paediatric but validated for use in } \\
\text { adolescents and used previously } \\
\text { in adults }[6,7]\end{array}$ & 14 \\
\hline PedsQL ${ }^{\mathrm{TM}}$ Multidimensional Fatigue Scale & $\begin{array}{l}\text { General } \\
\text { Fatigue } \\
\text { Sleep } \\
\text { Fatigue } \\
\text { Cognitive } \\
\text { Fatigue }\end{array}$ & Fatigue Measure & Age specific scales & 30 \\
\hline Perceived Stress Scale & 10 & Perception of 'stress' & Adolescents \& Adults & 30 \\
\hline $\begin{array}{l}\text { Global Self Worth (subscale from 'Self- } \\
\text { perception Profile for Children') [8] }\end{array}$ & 6 & Self-esteem & Children aged $8 \mathrm{yr}-14 \mathrm{yrs}$ & 60 \\
\hline Rosenberg Self Esteem [9] & 10 & Self-esteem & Adults & 60 \\
\hline $\begin{array}{l}\text { REM Sleep Behaviour Disorder } \\
\text { Questionnaire [10] }\end{array}$ & 10 & $\begin{array}{l}\text { Detection of REM Sleep } \\
\text { Behaviour Disorder }\end{array}$ & Adults & Baseline \\
\hline Pittsburgh Sleep Quality Index [11] & 7 & $\begin{array}{l}\text { Identification of problematic } \\
\text { sleep }\end{array}$ & Adults & Baseline \\
\hline Sleep Disturbance Scale for Children [12] & 6 & $\begin{array}{l}\text { Identification of type of sleep } \\
\text { disorder in children }\end{array}$ & Children & Baseline \\
\hline
\end{tabular}

Since this pilot study there have been significant changes to the underlying technology, with the aim to simplify and improve the user experience. Based on the feedback of the wearable device specifically, another device has also been selected which meets much of the informal feedback offered by patients. Ability for doctors to $\log$ on to system during clinic to review all data is also now possible.

The technology however is beneficial to both clinical patient care and research. It makes participation in care and research accessible to patients and offers timely feedback to clinical and academic teams using methodologies increasingly familiar to both parties in a technologically advancing society.

\section{Conclusions}

This pilot dataset has demonstrated both the feasibility and utility of this approach to disease assessment which addresses many of the unmet needs in this patient group. An expanded study with consideration of the practical and logistic limitations identified is required to adopt this into both clinical and research environments with subsequent expansion across disease areas.

\section{Methods}

Patients were recruited from specialist UK centres and through the UK Gaucher Association. Patients with a genetic and biochemical diagnosis of Gaucher Disease over the age of 5 years, ambulant and who were able to comply with at least three of the study procedures were approached for participation.
Patient demographics and disease state are presented in Table 8.

Baseline clinical assessments included a neurological examination, the mSST, 6 Minute Walk Test (6MWT) and GAITIRite or Zeno Walkway gait analysis. The GAITRite/Zeno Walkway gait systems are transportable walkways embedded with pressure sensors which detect footfall in realtime allowing measurement of stance, gait velocity, balance and weight distribution amongst a range of more complex gait parameters.

Although the mSST was designed specifically to evaluate the neurological manifestations of patients with nGD, mSST scores derived from the neurological examination of type 1 Gaucher patients were also generated for the purposes of comparison. The domains evaluated in the mSST are standard neurological disease features which collectively are relevant to nGD but are not exclusive to the disorder, e.g. seizures accounts for one domain but seizures have multiple causes. In addition, the kyphosis domain scored in the mSST also occurs in nonneurological disease (type 1 patients) secondary to bone disease of the vertebrae and may impact on activity.

The 6MWT was completed on a $25-\mathrm{m}$ track following a standardised trial procedure. $\mathrm{Z}$ scores were calculated to summarise the data, using reference ranges for age and gender generated by Geiger et al. [3]; the z-score was calculated by subtracting patient scores for the reference values for age and sex [3] and divided by the standard deviation of those reference values.

All consenting patients downloaded the Aparito application (App) to their own or their parents' mobile 
phone. This app was paired with a 3D accelerometer device (Million pedometer) to be worn on the wrist and patients were encouraged to keep this in situ at all times for the duration of the study; minimum of 2 weeks, maximum of 12 months. The accelerometer device captured data in $30 \mathrm{~min}$ epochs and calculated the number of steps taken for that 30-min period. The paired app pushed out Patient Reported Outcomes (PROs) and Quality of Life (QoL) scales at pre-set intervals ranging from fortnightly to every 2 months. Table 9 lists the PROs and the frequency in which they were sent out.

Patients could also record visits to health care professionals, other 'events' e.g. falls, seizures etc. and they were encouraged to offer detail of sleep quality. Sleep was evaluated on paper-based questionnaires using validated tools at baseline and report episodes of poor sleep through the phone app in real-time.

\section{Acknowledgements}

The authors would like to acknowledge the contributions of Mario Cortina, Helen Whitehead, Kathy Page, Pauline Hensman, James Skinner, Lucy Alderson and Phillip Hariness.

\section{Authors' contributions}

$A D$ analysed the data and was a major contributor in writing the manuscript. $\mathrm{HC}$ performed data analysis. NF conducted patient recruitment and historical data collection. TC facilitated the patient focus groups, and contributed to funding and recruitment. DH reviewed the manuscript and contributed to patient recruitment. ED contributed to data analysis and writing the manuscript. All authors read and approved the final manuscript.

\section{Funding}

Funded by Gaucher Association UK with time contributed by AD through an educational project (PhD).

\section{Availability of data and materials}

The datasets used and/or analysed during the current study are available from the corresponding author on reasonable request.

\section{Ethics approval and consent to participate}

All participants gave informed consent, and the study was approved by the Wales Research Ethics Committee 5 Bangor (REC Ref. 16/WA/0129), IRAS ID: 192163.

\section{Consent for publication}

Consent for publication was obtained from participant 005.

\section{Competing interests}

Dr. Donald has received honoraria for speaking and consulted on advisory boards with Sanofi and Oxyrane; Professor Hughes has received honoraria for speaking and advisory boards from Sanofi and Takeda; Dr. Davies is employed by Aparito and has shares with Aparito, she has offered consultancy with Prevail, Oxyrane, Lysogene and Amicus; Niamh Finnegan has received honoraria from Takeda, Amicus, Biomarin and Sanofi Genzyme Tanya Collins-Histed has received honoraria and travel and research grants from Prevail, Oxyrane and Shire.

\section{Author details}

${ }^{1}$ University of Manchester, St Marys Hospital, Manchester, UK. ${ }^{2}$ Aparito, London, UK. ${ }^{3}$ The Royal Free London NHS Foundation Trust, London, UK. ${ }^{4}$ Gaucher Alliance, Dursley, UK.
Received: 12 June 2019 Accepted: 16 August 2019

Published online: 05 September 2019

\section{References}

1. Wong K, et al. Neuropathology provides clues to the pathophysiology of Gaucher disease. Mol Genet Metab. 2004:82:192-207.

2. Davies EH, et al. Four-year follow-up of chronic neuronopathic Gaucher disease in Europeans using a modified severity scoring tool. J Inherit Metab Dis. 2011:34:1053-9.

3. Geiger $\mathrm{R}$, et al. Six-minute walk test in children and adolescents. J Pediatr. 2007;150:395-399.e2

4. Block VJ, et al. Continuous daily assessment of multiple sclerosis disability using remote step count monitoring. J Neurol. 2017;264:316-26.

5. Hamed A, Curran C, DasMahapatra P. Monitoring physical activity using a wearable device in Pompe disease. Neuromuscul Disord. 2017:27:S163.

6. Stevens K. Valuation of the child health utility $9 D$ index. PharmacoEconomics. 2012;30:729-47.

7. Stevens K. Assessing the performance of a new generic measure of healthrelated quality of life for children and refining it for use in health state valuation. Appl Health Econ Health Policy. 2011;9:157-69.

8. Granleese J, Joseph S. Reliability of the Harter self-perception profile for children and predictors of global self-worth. J Genet Psychol. 1994;155:487-92

9. Robins RW, Hendin HM, Trzesniewski KH. Measuring global self-esteem: construct validation of a single-item measure and the Rosenberg selfesteem scale. Personal Soc Psychol Bull. 2001:27:151-61.

10. Stiasny-Kolster $\mathrm{K}$, et al. The REM sleep behavior disorder screening questionnaire-a new diagnostic instrument. Mov Disord. 2007;22:2386-93.

11. Buysse DJ, Reynolds CF III, Monk TH, Berman SR, Kupfer DJ. The Pittsburgh sleep quality index: a new instrument for psychiatric practice and research. Psychiatry Res. 1989;28:193-213.

12. Bruni $\mathrm{O}$, et al. The sleep disturbance scale for children (SDSC) construct ion and validation of an instrument to evaluate sleep disturbances in childhood and adolescence. J Sleep Res. 1996;5:251-61.

\section{Publisher's Note}

Springer Nature remains neutral with regard to jurisdictional claims in published maps and institutional affiliations.

\footnotetext{
Ready to submit your research? Choose BMC and benefit from:

- fast, convenient online submission

- thorough peer review by experienced researchers in your field

- rapid publication on acceptance

- support for research data, including large and complex data types

- gold Open Access which fosters wider collaboration and increased citations

- maximum visibility for your research: over $100 \mathrm{M}$ website views per year

At BMC, research is always in progress.

Learn more biomedcentral.com/submissions
} 